\title{
Structure Analysis of CoPt Nanoparticles
}

\author{
Y. H. Huang*, Y. Zhang ${ }^{*}$, C. E. Nelson**, G. C. Hadjipanayis*, and D. Weller*** \\ * Department of Physics, University of Delaware; Newark, DE 19716; \\ **NCEM, Lawrence Berkeley National Laboratory, Berkeley, CA 94720 \\ *** Seagate Technology; Pittsburgh, PA 1520;
}

Introduction: In this study we investigated the structure and microstructure evolution of CoPt nanoparticles (size $<10 \mathrm{~nm}$ ) with heat treatment. The magnetic properties of nanoparticles are studied and correlated to their structural properties.

Sample Preparation: The $\mathrm{CoPt} / \mathrm{C}$ multilayered films were prepared by dc magnetron sputtering from solid CoPt and $\mathrm{C}$ targets onto $\mathrm{Si}$ (111) substrates using the tandem mode. The sample was postannealed at $700^{\circ} \mathrm{C}$ in order to break the multilayers and form the ordered $\mathrm{L} 1_{0}$ phase nanoparticles. Structure of the films was examined with a Jeol JEM-2000FX Transmission Electron Microscope (TEM) and a Philips CM20 X-Ray Diffractometer (XRD).

Brief Summary of Results and Discussion: All the as-made films are magnetically soft. The films consist of the fcc CoPt phase with very small grain size about $3 \mathrm{~nm}$. L1 $1_{0}$ structured CoPt nanoparticles are formed after annealing at $700^{\circ} \mathrm{C}$ with coercivity up to $14 \mathrm{kOe}$. (Fig.1-3). The particle coercivity is are found to have an approximately linear dependence on particle size after initial annealing. Figure 3a shows the coercivity development in films with different composition ratio. Films with high matrix content showed smaller coercivities due to the fact that the particle size growth is limited by excessive matrix element. Figure $3 \mathrm{~b}$ shows the corresponding microstructure evolution for films with equal volume amount of $\mathrm{CoPt}$ and $\mathrm{C}$. The early stage of annealing (5 minutes) leads to the appearance of the ordered fct phase without much increase in the average particle size, which is about 3-5 $\mathrm{nm}$ from the TEM studies. Optimum annealing (with a coercivity in the range 3-8 kOe and optimum hysteresis shape) led to particles with size of about 8-10 nm and prolonged annealing ( 1 hour) to particles with a higher degree of ordering (as can be seen in the SAD patterns) and a much larger particle size. Fitting the high field $\mathrm{M}(\mathrm{H})$ data (Fig. 2) to the law of approach to saturation gave a saturation magnetization $\left(\mathrm{M}_{\mathrm{s}}\right)$ of $779 \mathrm{emu} / \mathrm{cc}$ and an anisotropy constant $\left(\mathrm{K}_{\mathrm{u}}\right)$ of $9.2 \times 10^{6} \mathrm{ergs} / \mathrm{cc}$ at low temperature which leads to a calculated coercivity of $11 \mathrm{kOe}$. The small dip in the hysteresis loop at a small negative field and the small difference between the experimental and calculated value of coercivity $(9.2$ and $11 \mathrm{kOe})$ are consistent with the Mössbauer spectra analysis in annealed FePt nanoparticles which showed a small amount of fcc phase still present. Cross-sectional TEM and HRTEM images (Fig. 4) at different annealing stages showed that the multilayers are broken and forming the CoPt particles very early and that prolonged annealing leads to particle growth and phase transformation and finally into randomly oriented single crystal particles embedded within amorphous $\mathrm{C}$ matrix.

\section{References}

[1] S. Sun, C. B. Murray, D. Weller, L. Folks, and A. Moser, Science, 287, (2000) 1989

[2] J. A. Christodoulides, et. al., IEEE Trans. Magn., 37, (2001) 1292

[3] This research was supported by Seagate Technology and National Science Foundation under Grand No. NSF-DMR 9972035. 

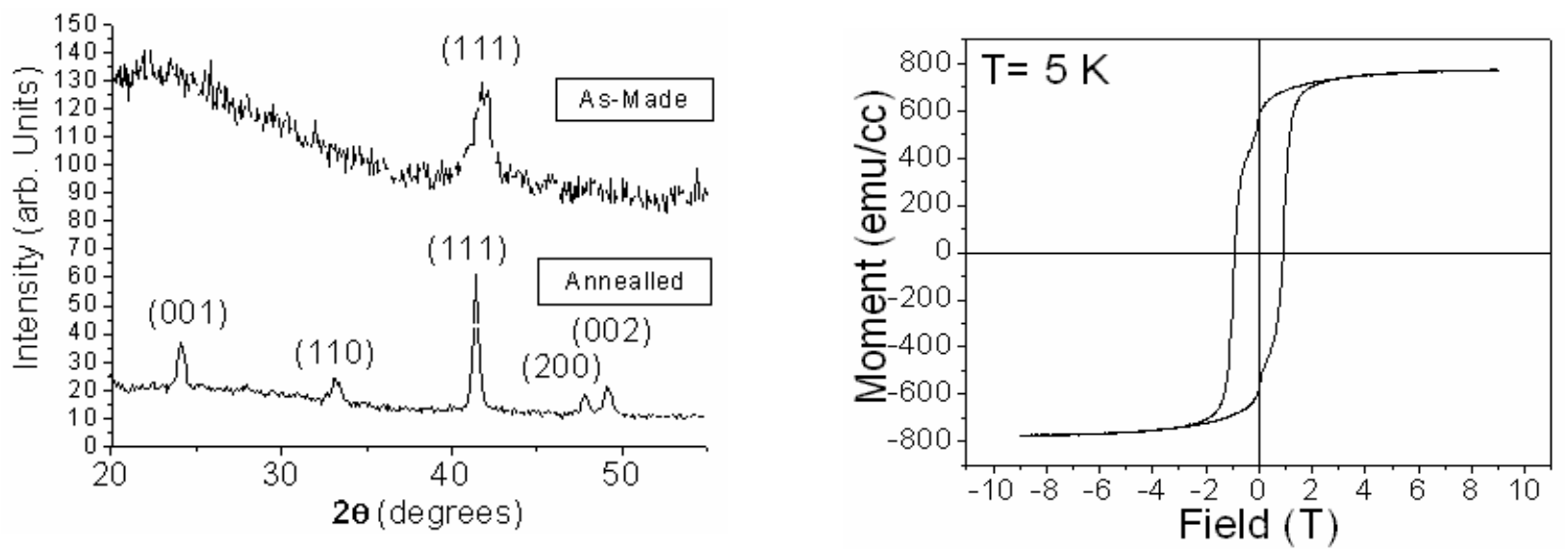

FIG. 1. (left) XRD pattern for as-made and annealed $\left(700^{\circ} \mathrm{C}\right.$ for 1 hour $) \mathrm{CoPt} / \mathrm{BN}$ films with bilayer thickness of $(5 \AA / 5 \AA) \times 100$.

FIG. 2. (right) High field measurement loops of $\mathrm{CoPt} / \mathrm{C}$ films annealed at $700^{\circ} \mathrm{C}$ for 15 minutes.
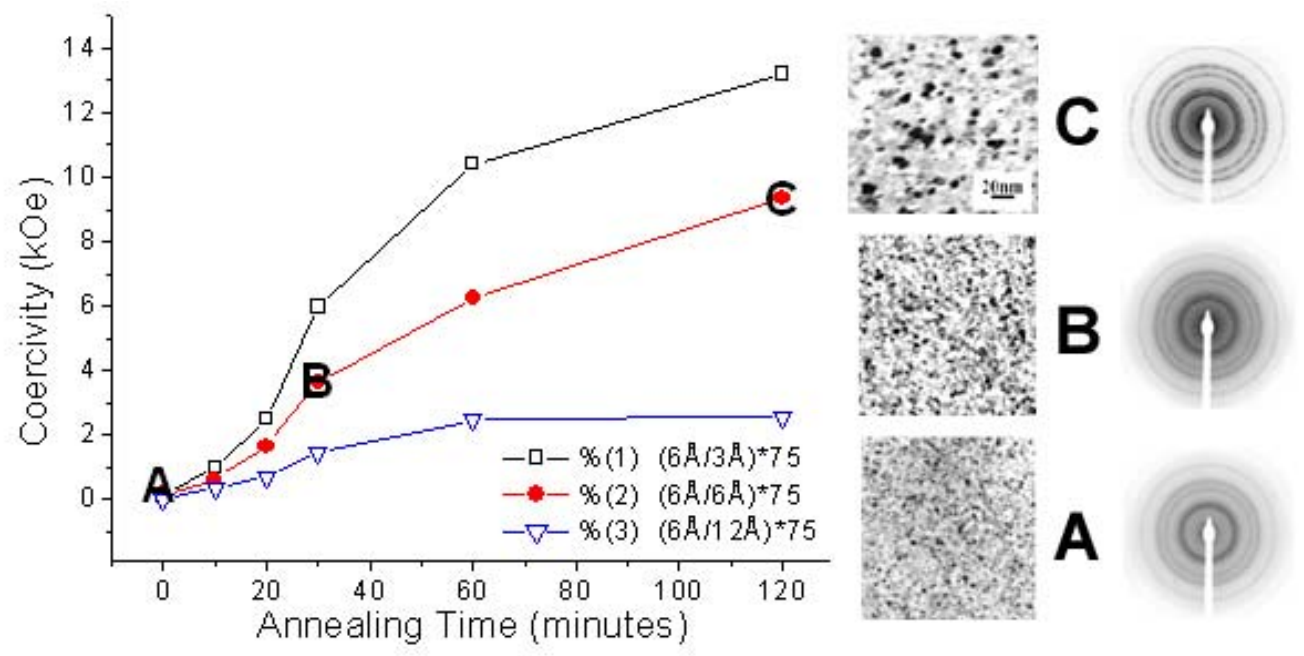

FIG. 3. Coercivity of $\mathrm{CoPt} / \mathrm{C}$ for different carbon ratios and particle size development due to annealing
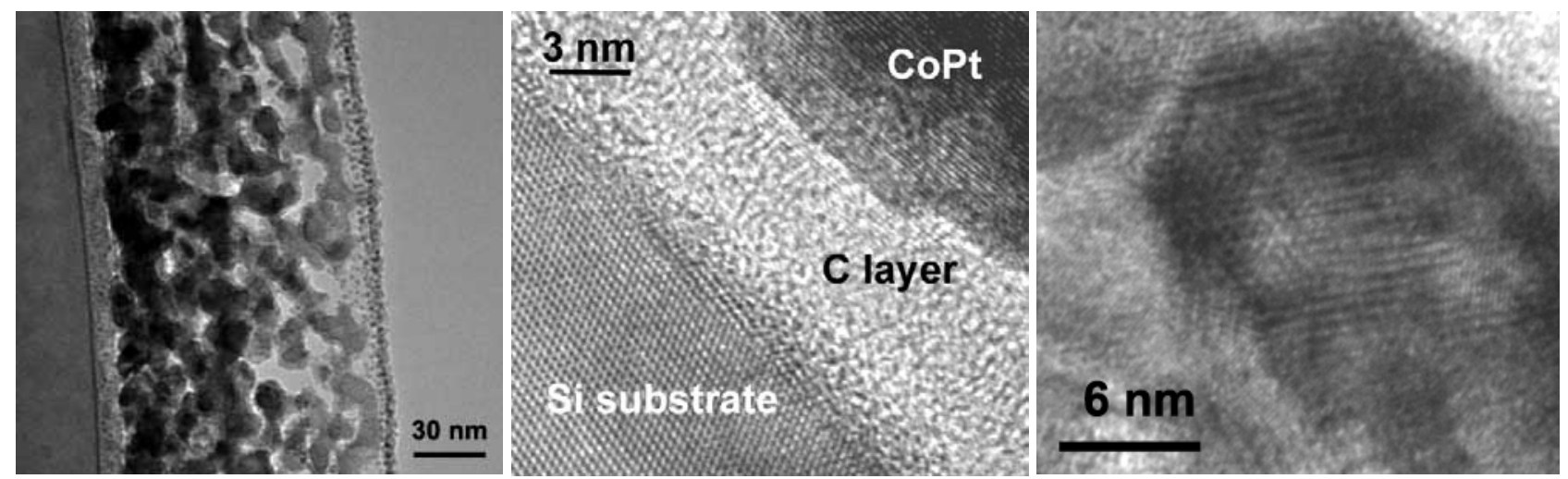

FIG. 4. High resolution TEM image of CoPt/C films (left, cross-sectional view showed broken of multilayers after 10 minutes of annealing at $700^{\circ} \mathrm{C}$, center, cross-sectional view of $\mathrm{CoPt} / \mathrm{C} / \mathrm{Si}$ interface, and right, planar view of single $\mathrm{CoPt}$ particle) 